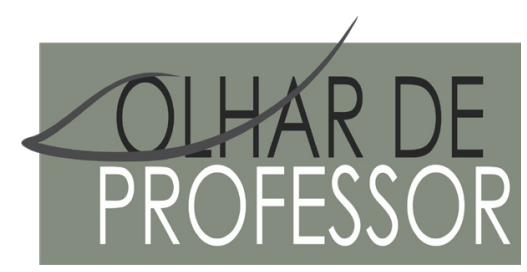

DOI: 10.5212/OLHARPROFR.v.23.2020.15176.209209224411.0419

\title{
A LINGUAGEM E A CONSTRUÇÃO DO REAL PELA CRIANÇA: CONTRAPONTOS ENTRE LEV S. VYGOTSKY E JEAN PIAGET
}

\author{
THE LANGUAGE AND THE CONSTRUCTION OF THE REAL BY THE CHILD: COUNTERPOINTS BETWEEN LEV S. \\ VYGOTSKY AND JEAN PIAGET
THE LANGUAGE AND THE CONSTRUCTION OF THE REAL BY THE CHILD: CONTRAPUNTOS ENTRE LEV S. VYGOTSKY Y JEAN PIAGET

\author{
MÉRITI DE SOUZA* \\ DIANA CARVALHO DE CARVALHO ${ }^{\text {** }}$
}

\begin{abstract}
Resumo: As teorias formuladas por Jean Piaget e Lev S. Vygotsky exerceram grande influência na formação de professores e debates sobre alfabetização, no Brasil, ao longo do século XX. Os contrapontos entre esses autores sobre a relação entre linguagem e construção do real pela criança é o foco do presente artigo, especialmente, no que diz respeito às diferenças entre desenvolvimento e aprendizagem e pensamento e linguagem. Compreende-se que a linguagem possibilita a comunicação com o outro e consigo mesmo, na medida em que viabiliza a materialização da nossa sensibilidade e a codificação e sistematização da realidade; a sua codificação passa, não só pelo domínio, mas, sobretudo, pela apreensão e recriação desse código linguístico.
\end{abstract}

Palavras-chave: Psicologia da Educação. Linguagem. Piaget e Vygotsky.

Abstract: The theories developed by Piaget and Vygotsky had great influence in teacher training and debates on literacy in Brazil along the $20^{\text {th }}$ century. This essay is focused on the counterpoints between these authors concerning the relationship between language and construction of the real by the child, especially regarding the differences between development and learning, and thought and language. It is understood that language allows for the communication with the other and with oneself, as it enables the materialization of our sensitivity, as well as the coding and systematization of reality; its coding goes through not only the mastering, but also by the grasping and re-creation of this linguistic code.

Keywords: Educational Psychology. Language. Piaget and Vygotsky.

Resumen: Las teorias formuladas por Piaget y Vygotsky ejercieron una gran influencia en la formación de profesores y en los debates sobre alfabetización en Brasil a lo largo del siglo XX. Los contrapuntos entre estos autores sobre la relación entre lenguaje y construcción de lo real por el niño son el foco del presente ensayo, especialmente en lo que se refiere a las diferencias entre desarrollo y aprendizaje y pensamiento y lenguaje. Se entiende que el lenguaje posibilita la comunicación con el otro y consigo mismo, en la medida en que hace viable la materialización de nuestra sensibilidad y la codificación y sistematización de la realidad; su codificación pasa, no sólo por el dominio, sino sobre todo, por la aprehensión y recriación de este código linguístico.

Palabras-clave: Psicología educativa. Lenguaje. Piaget y Vygotsky.

\footnotetext{
* Doutora em Psicologia pela Pontifícia Universidade Católica de São Paulo (PUC-SP). Professora no Programa de Pós-Graduação em Psicologia da Universidade Federal de Santa Catarina (UFSC). E-mail: meritisouza@yahoo.com.br

** Doutora em Educação pela Pontifícia Universidade Católica de São Paulo (PUC-SP). Professora titular da Universidade Federal de Santa Catarina (UFSC), credenciada no Programa de Pós-Graduação em Educação da mesma instituição.

E-mail: dianacc@terra.com.br
} 


\section{INTRODUÇÃO}

O século XX tornou-se conhecido como o século da criança, como indica Cambi (1999). De um lado, os estudos sobre desenvolvimento e aprendizagem tornaram-se o foco de várias teorias psicológicas que buscavam na Biologia e na teoria evolucionista os fundamentos para essa compreensão. De outro, tais estudos decorreram de necessidades práticas, como a implantação da escolarização universal na Europa, conforme evidencia Leite (1972, p. 91): “no momento em que todas as crianças são levadas para a escola, surgem três problemas que ainda hoje constituem preocupações centrais de psicólogos e pedagogos: a inteligência, a aprendizagem e, de maneira mais ampla, o problema das diferenças individuais”. Warde (1997) demonstra que a centralização dos estudos sobre a criança possibilitou a articulação entre a Psicologia e a Pedagogia como campos disciplinares na formação de professores, no final do século XIX e início do século XX.

No Brasil, a Psicologia, junto com a Biologia e a Sociologia, constituíram o que Lourenço Filho (1930) chamou, na década de 1930, de Ciências da Educação, exercendo forte impacto na formação de professores no país, como demonstram Sganderla e Carvalho (2010), no momento em que se consolidava o sistema educacional brasileiro.

As teorias psicológicas continuaram sendo hegemônicas na formação de professores no Brasil ao longo do século XX, com prevalência de algumas delas em determinados momentos históricos. A partir da década de 1960, a teoria formulada por Jean Piaget foi importante referência para os estudos educacionais sobre o desenvolvimento da criança (VASCONCELOS, 1996); a partir dos anos de 1990, esse espaço passa a ser ocupado também pela Psicologia Histórico-Cultural, especialmente a obra de Lev. S. Vygotsky (FREITAS, 1994).

O embate entre essas duas teorias, a perspectiva construtivista de Piaget e a teoria histórico-cultural de Vygotsky, foi tema que ocupou o centro da produção teórica sobre Psicologia e Educação no Brasil (PALANGANA, 1994; CASTORINA et al., 1998; DUARTE, 2000a, 2000b; SMOLKA, 2002). De forma específica, essas duas teorias também assumem lugar de relevância nos debates realizados no campo da linguagem e da construção do real pela criança, ou seja, a linguagem está relacionada à representação que a criança faz do mundo e, no âmbito geral da educação, essa questão atravessa o campo da escolarização.

Importa esclarecer que, dada à própria dimensão deste artigo e os objetivos por nós delineados, restringir-nos-emos a discutir essas questões no âmbito da Psicologia da Educação, particularmente, no âmbito das teorias do desenvolvimento infantil. Entretanto, destacamos a dimensão interdisciplinar do tema, bem como a dimensão da própria Psicologia, que necessita de referenciais históricos, filosóficos, sociológicos para a compreensão do fenômeno humano e, portanto, entendemos necessária a explicitação de alguns parâmetros e conceitos que possam delinear nossa concepção em um âmbito mais abrangente. Ou seja, neste artigo propomos recorrer a análise em textos selecionados de Piaget e Vygotsky que abordam as teorias sobre realidade e linguagem, para pensarmos suas relações com a prática pedagógica, no caso específico com a concepção de que essa prática demanda por parte do professor conhecer essas teorias. Para realizar essa empreitada, recorremos aos conceitos analíticos de realidade e de linguagem, apresentamos as concepções sobre esses conceitos que orientam a nossa análise nesse artigo.

Dessa forma, na medida em que enfocamos o conceito de realidade, que é tão controverso, cumpre apontar que nos apoiamos na concepção realista para a sua compreensão, entendendo a um nível ontológico a existência de um mundo objetivo, que existe independente do fato do indivíduo vir a conhecê-lo ou não, concordando com a concepção epistemológica acerca de que o indivíduo se inclui no processo de conhecimento, construindo-o, sendo que essa posição não se revela incongruente em relação à primeira, pois avaliamos que "[...] ambas se referem a coisas diferentes: uma, à existência dos fenômenos, e outra, ao conhecimento que deles se obtém” (BLEGER, 1980, p. 19).

Concordamos, ainda, com Berger e Luckmann (1985), quando indicam que a realidade é construída socialmente - sendo entendida como uma qualidade pertencente a fenômenos que reconhecemos ter um ser independente da nossa própria volição (não podemos “desejar que não existam”) -, bem como quando colocam o conhecimento como a certeza de que os fenômenos são reais e possuem características específicas. 
Os autores, partindo de uma perspectiva da sociologia do conhecimento, apontam-nos o processo de socialização, a partir da exteriorização, da objetivação e interiorização, enquanto processo de construção do real pelo ser humano. A exteriorização e a objetivação são entendidas como momentos contínuos desse processo, onde os produtos exteriorizados da atividade humana adquirem o caráter de objetividade.

O que nos interessa, particularmente, é a definição dada pelos autores à interiorização, sendo esta entendida como outro momento do processo de socialização, pelo qual o mundo social objetivado é reintroduzido na consciência, ou seja, onde o indivíduo apreende ou interpreta um acontecimento objetivo como dotado de sentido, como manifestação de processos subjetivos. Além disso, a socialização divide-se em primária e secundária. A primeira é aquela que se realiza na infância e implica em um aprendizado afetivo, pois a criança se identifica e vincula-se ao outro significativo, ou seja, ela interioriza os papéis e as atitudes do outro, posteriormente, ela abstrai e generaliza esses papéis e atitudes para o âmbito mais geral da sociedade, sendo esta abstração e generalização chamada o outro generalizado. Exemplificando: inicialmente, a criança discrimina que a mãe está zangada, posteriormente, discrimina que a mãe fica zangada quando ela derrama a sopa e, finalmente, conclui que não deve derramar a sopa. De acordo com Berger e Luckmann (1985, p. 179),

[...] quando o outro generalizado cristalizou na consciência, estabelece-se uma relação simétrica entre a realidade objetiva e a subjetiva. Aquilo que é real "fora" corresponde ao que é real "dentro". A realidade objetiva pode ser facilmente "traduzida" em realidade subjetiva, e vice-versa. A linguagem evidentemente é o principal veículo deste progressivo processo de tradução em ambas as direções.

O processo de socialização primária termina quando o indivíduo estabelece o conceito do outro generalizado e inicia-se a socialização secundária, entendida como: “[...] interiorização de 'submundos' institucionais ou baseados em instituições. A extensão e caráter destes são, portanto, determinados pela complexidade da divisão do trabalho e a concomitante distribuição social do conhecimento" (BERGER; LUCKMANN, 1985, p.184-185).

A socialização secundária assenta-se em uma aprendizagem, uma construção do conhecimento mais cognitiva, assim, o conhecimento interiorizado durante a socialização secundária é mais passível de questionamento do que o conteúdo adquirido durante a socialização primária, pois este adquire um caráter de realidade, de verdade subjetiva extremamente forte para o indivíduo. Dessa forma, tratando-se da realidade, podemos entendê-la como:

[...] socialmente edificada através da institucionalização, por este jogo dialético da reificação, apresenta-se então aos homens como um dado objetivo e coercitivo, que lhes determina a consciência. Em linhas gerias, pode-se notar que este processo possui três momentos: 1) a conduta humana é tipificada e padronizada em papéis, o que implica o estabelecimento das instituições (a realidade social é um produto humano); 2) a realidade é objetivada, ou seja, percebida como possuindo vida própria (o produto - a realidade - "desliga-se” de seu produtor - o homem); 3) esta realidade tornada objetiva determina a seguir a consciência dos homens, no curso da socialização. Isto é, no processo de aprendizagem do mundo por que passam as novas gerações (o homem torna-se produto daquilo que ele próprio produziu) (BERGER; LUCKMANN, 1985, p. 44).

Avaliamos como importante a discussão entabulada acima para situar, fundamentadas em Bleger (1980) e Berger e Luckmann (1985), nossa concepção de realidade, bem como o processo pelo qual a criança constrói sua concepção de realidade, pois esses autores nos permitem ressaltar a importância dos condicionantes históricos e sociais nesse processo. Entendemos como importante essa discussão, pois avaliamos que o referencial teórico utilizado demanda autores que se preocupem com a contextualização histórica e social que envolve a produção do conhecimento no âmbito das ciências humanas e sociais.

Tratando-se da questão específica da linguagem oral e escrita, encontramos em Kato (1987) um debate extremamente pertinente à análise dessa questão, uma vez que a autora a discute se utilizando entre outros referenciais, da contextualização sócio-histórica. Para a autora, a fala representa ideias, conceitos, sendo uma tentativa de codificação da realidade que permite a satisfação de necessidades humanas, como a necessidade individual de expressão e a social de comunicação. Inicialmente, temos a fala pré-letramento, 
denominada fala e, a seguir a escrita, que tenta representar a fala da maneira mais próxima possível; num outro momento, a escrita seria aquela que, em função de regras rígidas, praticamente se separa da fala e, finalmente, a fala seria aquela que prevalece após o processo de inserção do sujeito no mundo letrado.

A tese de Kato (1987, p. 11) é que “[...] a fala e a escrita são parcialmente isomórficas, mas que, na fase inicial, é a escrita que tenta representar a fala - o que faz de forma parcial - e posteriormente é a fala que procura simular a escrita, conseguindo-o também parcialmente”. Dessa forma, é através de uma representação de primeira ordem - onde as figuras representam diretamente as coisas - que o homem inicia a simbolização do real, para, em seguida, simbolizá-lo através de uma representação de segunda ordem, ou seja, a fala constitui-se ao reportar-se ao conceito que, por sua vez, reporta-se ao objeto.

Na história do homem, encontramos diferentes usos para a fala e a escrita. Inicialmente, a oralidade dispunha de um grande prestígio e era utilizada, entre outros aspectos, para a transmissão de conhecimento coletivo e para o entretenimento (estórias, conversas etc.). A necessidade do homem de registrar transações comerciais, fatos, enfim, de registrar dados facilmente esquecíveis - pois ligados a situações particulares e imediatas - leva-o a desenvolver um sistema de registro, que vai desde a utilização de contas de barro até o surgimento dos primeiros sistemas.

A escrita era entendida, inicialmente, como estando sujeita a deturpações, sendo a linguagem oral privilegiada enquanto fonte fidedigna para a transmissão de conhecimentos. Essa situação se alterou progressivamente, particularmente, a partir da reforma luterana, onde a Bíblia (linguagem escrita) se consagra enquanto fonte incontestável de conhecimento.

Nas sociedades atuais, encontramos sociedades altamente letradas, onde predomina a utilização da linguagem escrita, bem como sociedades em fase de transição e aquelas onde predomina a forma oral. Observa-se que ocorre, nas sociedades letradas, uma distribuição da linguagem oral e escrita e essa distribuição muda com a evolução histórica sendo, em parte, determinada pelas diferenças sociais funcionais e pela variação individual.

Tratando-se do Brasil, Kato (1988) levanta a hipótese de que prevalece a linguagem oral em detrimento da escrita em função da extensão geográfica, onde setores do sul e sudeste, sobretudo, e das zonas urbanas apresentariam a primazia da escrita; em contrapartida, em extensas áreas rurais analfabetas prevalece a utilização da linguagem oral. A autora considera que, em longo prazo, o que pode acontecer no Brasil é uma adaptação da escrita à fala, da mesma maneira que, nas sociedades altamente letradas, ocorre uma tendência à assimilação da fala à escrita.

Ao discutir as relações entre linguagem oral e escrita, Kato (1988) dialoga com vários autores acerca dessa questão para, após, posicionar-se, destacando que não podemos entender a linguagem escrita apenas como um conjunto de regras e normas preestabelecidas e dissociadas da linguagem falada. As diferenças atribuídas a essas modalidades dizem mais a respeito das diferenças formais que tem a ver com o seu uso. Nas palavras da autora:

As modalidades oral e escrita da linguagem apresentam uma isomorfia parcial, porque fazem a seleção a partir do mesmo sistema gramatical e podemos expressar as mesmas intenções. O que determina as diferenças entre elas são as diferentes condições de produção, tais como: a dependência contextual, o grau de planejamento, a submissão consciente às regras prescritivas convencionalizadas para a escrita (KATO, 1987, p. 30).

Outra questão importante nesse debate e também controversa diz respeito à aquisição da linguagem oral e escrita. As hipóteses sobre a aquisição da linguagem se dividem, principalmente, entre as que postulam que a língua é inata no homem - concepções inatistas - e aquelas que entendem que ela é adquirida culturalmente. Mesmo quando consideram que é aprendida, ou seja, transmitida culturalmente, muitos teóricos divergem acerca da natureza dessa aprendizagem. Por outro lado, em geral, as teorias da linguagem apresentam hipóteses em referência à sua aquisição, porém, não lidam, objetivamente, com a questão da escrita.

Neste artigo, buscamos efetivar uma pesquisa teórica sobre o processo de construção do real pela criança e a sua relação com a linguagem, com base em algumas obras de Jean Piaget (1970, 1973, 1975) e Lev S. Vygotsky (1991, 1993, 1995), em diálogo com alguns de seus comentadores. Estamos cientes 
da extensão das teorias produzidas por esses autores, nossa pretensão não é alcançar tal amplitude. A escolha das obras aqui pautadas se deve à estreita relação com a temática abordada, ao mesmo tempo em que permitem explicitar os fundamentos epistemológicos dos autores para explicação do processo de desenvolvimento e aprendizagem.

As diferenças entre os fundamentos epistemológicos que caracterizam as duas perspectivas teóricas, bem como a compreensão que a cultura exerce na constituição do sujeito são alguns dos aspectos abordados pelos pesquisadores nesse debate. Assim, nosso objetivo neste artigo não é reapresentar tais discussões, mas, sim, tratar de um aspecto específico: os contrapontos entre Jean Piaget e Lev S. Vygotsky a respeito da relação entre linguagem e construção do real pela criança, considerando a importância do professor conhecer essas teorias para o exercício efetivo do seu trabalho com a escolarização infantil.

Em outras palavras, neste artigo pretende-se refletir sobre a importância do trabalho do professor estar ancorado no seu conhecimento acerca das teorias sobre o desenvolvimento da criança, particularmente no que diz respeito ao conhecimento sobre a construção infantil da linguagem e da realidade. Considerando essa perspectiva, elegemos para apresentar nesse artigo duas teorias fundamentais sobre a questão central da aquisição da linguagem e da realidade, no caso, as teorias de Jean Piaget e Lev Vygotsky. Para tanto, nesse ensaio teórico trazemos à cena recortes das teorias desses autores, considerando que ambas, em que pesem suas divergências, são imprescindíveis para a compreensão da questão central apontada. Ato contínuo, refletimos acerca da nossa concepção de que é fundamental para o professor conhecer e compreender essas teorias para desenvolver seu trabalho pedagógico.

\section{ALGUNS CONTRAPONTOS ENTRE JEAN PIAGET E LEV S. VYGOTSKY COM RELAÇ̃̃̃ À QUESTÃO DA CONSTRUÇ̄̃O DO REAL E DA LINGUAGEM}

Como sabemos, a epistemologia genética é a ciência que procura explicar as origens do conhecimento e, para tanto, vale-se do método psicogenético, que busca compreender a gênese do conhecimento na história da humanidade (conhecimento do número, do espaço etc.), ao mesmo tempo em que se preocupa com a origem e desenvolvimento do conhecimento no indivíduo, ou seja, essa epistemologia se preocupou em mostrar que a ontogênese do conhecimento repete a filogênese.

Podemos dizer que Piaget criou uma teoria do conhecimento que tem seu embasamento na Biologia e que trata acerca da construção da inteligência do ser humano; procura explicar como a criança se torna capaz de estruturar o real, construindo, inicialmente, as noções espaço-temporais e causais, tornando-se capaz, ao longo de seu desenvolvimento, de representar o que estruturou e verbalizar o que representou.

O conhecimento, para o autor, é gerado a partir da necessidade de conhecer, isto é, o ser humano possui estruturas cognitivas que o levam a buscar o conhecimento. Ele preocupou-se em compreender o instrumental que possibilita ao homem construir o conhecimento, relacionando-o com estrutura cognitiva e com a inteligência. A cognição é a própria inteligência, que, por sua vez, a partir do desenvolvimento biológico do homem e de sua interação com o meio, proporcionar-lhe-á condições de representar a realidade.

Conforme Piaget, o organismo é composto de estruturas programadas (estruturas orgânicas), estruturas parcialmente programadas (sistema nervoso) e estruturas específicas para conhecer (estruturas da inteligência). A inteligência seria a capacidade do indivíduo de adaptar-se ao meio, sendo que, qualitativamente falando, as estruturas da inteligência das pessoas seriam as mesmas, diferenciando-se a partir da interação do indivíduo com o meio, a qual se dá através de meio de mecanismos de adaptação e assimilação, que são comuns em todos os estágios de desenvolvimento e levam à construção das estruturas, tanto biológicas quanto mentais.

A inteligência no ser humano se inicia na medida em que este tem que fazer sua primeira adaptação, como, por exemplo, respirar. Segundo Piaget, os mesmos mecanismos que o homem utiliza na sua adaptação biológica, ele utiliza na sua adaptação mental. A assimilação e a acomodação se constituem em processos inerentes à adaptação. Para nos adaptarmos, necessitamos assimilar um dado da realidade e, muitas vezes, precisamos modificar nossas estruturas, mas, ato contínuo, as estruturas incorporam esse novo dado, levando à nova acomodação, porém, em um nível superior de equilíbrio. 
Existem várias formas de conhecer-se o mundo. De acordo com Piaget (1975), o indivíduo conhece o mundo das seguintes formas:

a. Através da função implicativa, que corresponde à classificação e à seriação. Essa função supõe a indução, a qual está ligada ao conhecimento físico.

b. Através da função explicativa, que corresponde à noção do próprio objeto. Essa função presume a dedução, que está mais ligada ao conhecimento lógico-matemático.

Ainda, a função explicativa supõe relações contínuas (tempo, espaço, relação causa-efeito), pois trabalha com objetos infralógicos, e a função implicativa opera com objetos não contínuos. O conhecimento lógico-matemático é fruto da dedução, já que ele coordena as ações que viu serem realizadas sobre os objetos e o conhecimento físico é abstraído do próprio objeto. Cumpre esclarecer que entendemos aqui por objeto todos os seres existentes, sejam animados ou inanimados.

A criança, inicialmente, não tem consciência de si mesma e nem da ação que realiza, porque não existe intencionalidade e nem representação, que, no entanto, vai sendo elaborada a partir do seu envolvimento prático com o mundo, resultando na linguagem. É importante ressaltar que, para Piaget, a representação constrói-se tendo por base a estruturação pela criança do espaço, do tempo e da causalidade.

A intencionalidade aparece junto com a causalidade, a noção de objeto permanente e a representação mental da ação (entenda-se aqui ação como um comportamento que objetiva um determinado fim). Conforme Piaget, fala-se em consciência na criança quando ela elimina um obstáculo para atingir um fim; entretanto, a representação está ainda se constituindo.

A função simbólica é a capacidade da criança de evocar um significado sem a presença de um significante e a representação mental existe quando a criança dissocia o significado do significante. Entretanto, quando, por exemplo, a criança ouve "o barulho de uma chave e chora, reconhecendo que o pai vai sair", trata-se de um indício, pois a criança não apresenta representação mental, visto que o significante ainda não está dissociado do significado.

A função semiótica ou simbólica é a capacidade de representar um significado (objetos ou fatos) por meio de um significante (símbolos individuais ou coletivos), ou seja, consiste na representação de um significado qualquer - um objeto, um acontecimento, um esquema motor - por meio de um significante diferenciado e específico para esse fim. Essa função se caracteriza pelo surgimento - em torno do segundo ano do bebê - de condutas, tais como a imitação, o jogo simbólico, o desenho, a imagem mental e a linguagem.

Na concepção de Piaget (1975, p. 345), a gênese da representação estaria associada ao desenvolvimento da inteligência na criança, resultante do equilíbrio entre a assimilação e a acomodação e, dessa forma, "quem diz representação, diz consequentemente reunião de um 'significante' que permite a evocação e de um "significando” fornecido pelo pensamento. A instituição coletiva da linguagem é, em relação a isso, o fator principal e de formação e socialização das representações”.

Tratando-se da linguagem, a função simbólica é condição "sine qua non” para sua aquisição, que se inicia com a fase da lalação espontânea entre 6 e 10-11 meses, acompanhada, posteriormente, de uma fase de diferenciação de fonemas entre os 11-12 meses. No final do período sensório-motor surgem as "palavras-frases”, que permitem à criança exprimir desejos, emoções etc.

Na compreensão de Piaget, é a partir dos esquemas sensório-motores que se formam os primeiros esquemas verbais, que se constituem em intermediações entre os esquemas conceituais e os sensório-motores, caracterizando-se pela utilização pela criança de "palavras” intermediárias entre os símbolos e os signos.

Inicialmente, os conceitos ou esquemas verbais acompanham a ação, representando-a, e a linguagem, nessa fase, é ligada à ação imediata da criança. Posteriormente, a linguagem deixa de acompanhar a ação presente, para evocar a ação passada, ocorrendo que a palavra começa a funcionar como signo e o esquema verbal destaca-se do sensório-motor. Ainda, os pré-conceitos permanecem a meio caminho entre a generalidade do conceito e a especificidade dos elementos que o compõem.

Nesse período, que vai dos 2 aos 3 anos, a criança trabalha com pré-conceitos, dada sua dificuldade em compreender a existência de classes e de que os membros de uma mesma classe podem diferir 
e assemelhar-se entre si. Entretanto, por volta dos quatro aos oito anos vão surgindo os conceitos operatórios, em função de uma articulação do pensamento intuitivo.

Na fase pré-escolar, o que caracteriza o raciocínio infantil são as transduções, que se caracterizam por serem inferências que procedem do particular para o particular, são raciocínios que precedem a indução e a dedução. Finalmente, quando a criança atinge o estágio das operações lógico-formais, as transduções serão substituídas pelo pensamento lógico.

A capacidade da criança de aprender, que, para Piaget, pode ser entendida como a capacidade de empregar uma lógica, manifesta-se nas ações antes de manifestar-se na linguagem. Empregar a lógica seria a capacidade de resolver tarefas, utilizando a noção de conservação, classificando e seriando.

Piaget (1973) indica que a linguagem tem como função a evocação de situações e de objetos não atuais e não presentes, permitindo, assim, à criança de libertar-se das fronteiras do imediato e do presente, dado que a inteligência senso-motora se encontra praticamente confinada a esses limites. Todavia, ele claramente afirma que a linguagem não é a fonte do pensamento, sendo esta a função simbólica:

[...] a linguagem não é suficiente para explicar o pensamento, pois as estruturas que caracterizam esta última têm suas raízes na ação e nos mecanismos senso-motores que são mais profundos que o fato linguístico. [...]. A linguagem, portanto, é condição necessária, mas não suficiente para a construção das operações lógicas [...]. Entre a linguagem e o pensamento existe, assim, um ciclo genético, de tal modo que um dos dois termos se apóia necessariamente sobre o outro, em formação solidária e em perpétua ação recíproca. Mas ambos dependem, no final das contas, da inteligência que é anterior à linguagem e independente dela (PIAGET, 1973, p. 92).

Como vemos, para o autor, não é a linguagem que origina o pensamento lógico, mas, sim, as ações sensório-motoras; entretanto, ele reconhece a importância da linguagem nas adaptações apoiadas em representações e que fogem do âmbito do imediato, bem como a possibilidade do pensamento, via linguagem, possibilitar representações simultâneas de conjunto, visto que a inteligência sensório-motora procede por ações sucessivas e graduais.

A linguagem, na compreensão de Piaget, amplia e aprofunda a capacidade de compreensão, porém, não explica o desenvolvimento da inteligência; a linguagem seria o reflexo do desenvolvimento do pensamento infantil, sendo que os conceitos verbais não se formam pela transmissão verbal. Além disso, cumpre enfatizar que, nessa perspectiva, o conhecimento implica em ação, do sujeito sobre os objetos, que não pode ser substituído pela linguagem.

Para compreender os contrapontos entre Piaget e Vygotsky, cabe destacar o fato de que esses autores nasceram no mesmo ano, isto é, em 1896, mas produziram em contextos históricos e sociais muito distintos, o que, com certeza, implicou em diferenças nas suas escolhas teórico-metodológicas. Vygotsky vive a ambiência da revolução soviética de 1917, buscando a construção de uma Psicologia que se fundamentasse nas bases do materialismo histórico e dialético. Na ambiência cultural do final do século XIX e das primeiras décadas do século XX, os autores da Psicologia Histórico-Cultural destacaram-se pela crítica às formas de compreensão do objeto e método da ciência psicológica, vinculadas, tradicionalmente, às concepções filosóficas empirista e racionalista ${ }^{1}$.

Segundo Vygotsky (1991), nenhuma dessas concepções conseguia dar respostas efetivas ao estudo das funções especificamente humanas, que denominou funções psíquicas superiores, porque eram estudadas a partir dos processos naturais que as integram, reduzindo os processos superiores e complexos aos processos elementares (como os reflexos) e desprezando as peculiaridades e leis específicas do desenvolvimento cultural da conduta.

O autor define as funções psíquicas superiores como dois grupos de fenômenos que caracterizam as ações especificamente humanas, a saber: a) os processos de domínio dos meios externos do desenvolvimento cultural e do pensamento, tais como a linguagem, a escrita, o cálculo, o desenho; b) os processos de desenvolvimento das funções psíquicas especiais, como a atenção voluntária, a memória lógica e a formação de conceitos. (VYGOTSKY, 1995²).

\footnotetext{
${ }^{1}$ Para maior aprofundamento das críticas da Psicologia Histórico-Cultural às correntes psicológicas do início do século, consultar o texto “O significado histórico da crise da psicologia: uma investigação metodológica”, de Vygotsky, escrito em 1927. ${ }^{2} \mathrm{O}$ texto "História do desenvolvimento das funções psíquicas superiores” foi publicado originalmente em 1931.
} 
Na verdade, as concepções tradicionais em Psicologia não conseguiam explicar as diferenças entre os processos orgânicos e os processos culturais do desenvolvimento, por isso tendiam a considerá-los como fenômenos da mesma ordem, de idêntica natureza psicológica e com leis que se regeriam pelo mesmo princípio. Tal compreensão levava a uma formulação errônea das questões porque não julgava os fatos do desenvolvimento psíquico da criança como fatos do desenvolvimento histórico, mas, sim, como processos e formulações naturais, confundindo o natural e o cultural, o natural e o histórico, o biológico e o social $^{3}$ (VYGOTSKY, 1995).

Assim, as funções psíquicas, tais como a linguagem e o desenho infantis, o domínio da leitura e da escrita, o desenvolvimento e a representação das operações numéricas ou a formação de conceitos, que são funções complexas por sua natureza e funcionamento, eram estudadas sob a mesma lógica do aparecimento da dentição infantil, da maturação percepto-motora ou das mudanças hormonais na adolescência, aquisições reguladas pela maturação de processos biológicos.

Vygotsky (1995) também apontava a fragmentação dos processos psíquicos nos estudos realizados, em que se perdia seu caráter unitário estrutural, já que a análise do processo psíquico era feita a partir do resultado de suas partes ou dos elementos isolados. Em virtude dessa maneira predominante de abordar os problemas do desenvolvimento das funções psíquicas superiores da criança, a psicologia tradicional estudou, principalmente, as formas complexas de comportamento em diferentes estágios de desenvolvimento, em lugar de esclarecer a gênese dos processos psíquicos. Desse modo, prevaleceu a ideia de que o que se desenvolve não é a forma em sua unidade, mas seus elementos isolados que se modificam em cada momento diferenciado da vida.

Se recuperarmos o modo como tem sido encarada a aquisição da escrita pela criança, na psicologia tradicional, podemos entender as críticas teórico-metodológicas feitas por Vygotsky (1995): durante muito tempo, a escrita foi considerada uma habilidade mecânica que aparece por volta dos sete anos na criança, dependendo, basicamente, da maturação percepto-motora, e ensinada a partir de seus elementos isolados (aspectos visuais e auditivos). Perde-se, nessa compreensão, a dimensão de unidade do processo, desconhecendo-se sua gênese e desenvolvimento. O autor demonstra que a escrita tem uma pré-história, em que devem ser considerados como precursores o gesto infantil, as primeiras expressões do desenho e o jogo simbólico.

As peculiaridades da escrita como um processo cultural que caracteriza ações especificamente humanas também foram desconsideradas nesse tipo de abordagem, como também as mudanças que o domínio da alfabetização introduz no desenvolvimento do psiquismo infantil.

Para o estudo das funções psicológicas superiores, Vygotsky (1995) propunha o método genético-experimental, sendo suas características fundamentais: a) a análise do processo em lugar do objeto, ou seja, restabelecer geneticamente todos os momentos do desenvolvimento do processo psíquico e estudá-lo em movimento; b) realizar uma análise explicativa dos fenômenos e não apenas sua descrição, isto é, apresentar à vista as relações e os nexos causais existentes entre os diversos elementos de um processo psíquico, que estão por detrás da sua forma exterior e de suas manifestações; c) a preocupação da análise não se centrava no resultado acabado ou no produto do desenvolvimento, mas no próprio processo de aparição das formas superiores de conduta, ou seja, a indicação da origem desses processos.

Tal perspectiva metodológica implicava abordar o processo de desenvolvimento dos processos psicológicos em todas as suas fases e nuanças, desde o momento em que haviam surgido até seu desaparecimento, colocando em evidência sua natureza e essência. A compreensão histórica do desenvolvimento da espécie humana demandava, assim, considerar as funções psíquicas superiores a partir das etapas anteriores que as antecedem, pois as formas inferiores não se aniquilam, mas se incluem na etapa posterior e continuam existindo nela como instância subordinada ${ }^{4}$ (VYGOTSKY, 1995).

\footnotetext{
${ }^{3}$ Na filogênese, o desenvolvimento do comportamento biológico ou natural e o desenvolvimento do comportamento histórico ou cultural são processos que aparecem separados: os estudos do evolucionismo e da antropologia destinam-se a investigar cada um desses aspectos. Na criança, entretanto, esses dois planos se amalgamam, levando muitos estudiosos do desenvolvimento à confusão, descrita por Vygotsky, entre os aspectos biológicos e os aspectos culturais.

${ }^{4}$ Vygotsky (1995) aplica esses princípios teórico-metodológicos no estudo da evolução do funcionamento cerebral na espécie humana, evidenciando como os novos centros cerebrais passaram a regular as funções superiores e assumiram funções que eram dos centros inferiores, edificando sobre estes os novos comportamentos. Os centros inferiores não ficaram apartados dos superiores, mas subordinados a eles.
} 
Diferentemente da psicologia tradicional da época, que considerava o desenvolvimento infantil como um processo de mudanças isoladas, lentas e graduais, cuja tendência era a aquisição progressiva das diferentes habilidades e comportamentos, Vygotsky (1995) encarava como um complexo processo histórico e dialético, marcado por rupturas, saltos qualitativos, mudanças cruciais e revolucionárias. O desenvolvimento, segundo o autor, caracteriza-se pelas desproporções no desenvolvimento das diversas funções, pelas metamorfoses ou transformação qualitativa de umas formas em outras, pelo entrelaçamento complexo de processos evolutivos e involutivos, pelo complexo cruzamento de fatores externos e internos, pelo complexo processo de superação de dificuldades e adaptação.

Nesse sentido, constata-se que Vygotsky (1995) propunha, além de uma mudança de método na ciência psicológica, uma mudança de conteúdo, ou seja, uma maneira diferente de abordar a relação entre o biológico e o cultural: à medida que o desenvolvimento orgânico se produz em um meio cultural, passa a ser um processo biológico historicamente condicionado.

Ao enfatizar os aspectos culturais do desenvolvimento, o autor indica que a grande mudança na evolução da espécie humana foi, na verdade, qualitativa, que originou um novo tipo de conduta na história da humanidade e permitiu um salto dialético que alterou qualitativamente a relação entre estímulo e reação. A cultura originou formas especiais de conduta, modificou a atividade das funções psíquicas, edificou novos níveis no sistema de comportamento humano em desenvolvimento (VYGOTSKY, 1995).

A vida social, a interação entre os seres humanos, foram um dos principais fatores responsáveis por tal mudança qualitativa. No processo da vida social, o homem desenvolveu sistemas muito complexos de relação social e psicológica. Entre todos os sistemas criados pelo homem, o mais importante é a linguagem, pois permitiu a assimilação da experiência construída pela humanidade, o domínio da corticalidade cerebral e o controle do comportamento, tanto o próprio comportamento do homem como daqueles que o cercam (VYGOTSKY, 1995).

Luria (1991, p. 124) explica, com muita propriedade, porque a linguagem constitui a maior conquista do gênero humano, que diferencia os homens das outras espécies animais: “[...] para os animais há apenas evolução; com o homem começa a história e, com ela, os tipos de comportamento que podem ser considerados como produtos desta história social, e não como produtos biológicos”. O desenvolvimento mental proporcionado pela aquisição da experiência humano-social por meio da linguagem é um tipo de desenvolvimento que não existe nos animais. De acordo com o autor, a apropriação da experiência histórico-social da humanidade pelo indivíduo constitui a base de seu pensamento e da formação de sua personalidade.

A assimilação da linguagem acarreta transformações na relação da criança com o mundo e na sua própria organização mental, conforme afirma Luria (1991, p. 125):

Quando a criança assimila a linguagem, fica apta a organizar de nova maneira a percepção e a memória; assimila formas mais complexas de reflexão sobre os objetos do mundo exterior; adquire a capacidade de tirar conclusões das suas próprias observações, de fazer deduções, conquista todas as potencialidades do pensamento.

[...] Ao assimilar as palavras e ao usá-las, a criança analisa e sintetiza os fenômenos do mundo exterior, usa a experiência de todo o gênero humano e não só a sua experiência pessoal. A criança classifica objetos, começa a percebê-los diferentemente e assim recorda-os de maneira diferente.

Mas a linguagem adquirida da criança não consiste apenas em palavras isoladas, mas em combinações gramaticais complexas, em expressões completas. Estas expressões permitem não só a análise e a síntese da percepção, mas também a conexão de coisas com ações e, o que ainda é mais importante, permitem relacionar coisas entre si. Ao apossar-se de formas de discurso desenvolvido, a criança adquire a capacidade de formar conceitos, mas também de deduzir conclusões de uns supostos; assimila relações lógicas, conhece leis que estão muito para além dos limites da experiência pessoal direta; em conclusão, assimila a ciência e adquire a capacidade de prever e predizer fenômenos, coisa que não poderia fazer se se limitasse a ser uma simples testemunha. 
Em primeiro lugar, podemos identificar nas palavras de Luria (1995) uma tese defendida por Vygotsky e por todos os demais representantes da Psicologia Histórico-Cultural, que se opõe à tese defendida pela Psicologia Tradicional. Para a Psicologia Tradicional, a base a partir da qual se deduziam os comportamentos sociais era o comportamento individual do ser humano, ou seja, esse enfoque compreendia que a direção do desenvolvimento acontecia do individual para o social. Para os autores da Psicologia Histórico-Cultural, no entanto, a direção do desenvolvimento é inversa: o indivíduo nasce social e individualiza-se no decorrer do desenvolvimento, à medida que se apropria da experiência histórico-social da humanidade.

Tal apropriação não significa uma simples cópia do real, como compreendia o empirismo, mas uma relação dialética entre o indivíduo e a sociedade, relação esta em que o indivíduo se modifica sob a ação da experiência histórica coletiva, ao mesmo tempo em que também pode interferir na própria cultura e alterá-la com ações originais e criativas. A apropriação da experiência histórico-social sempre é individualizada, pois depende das vivências particulares de cada indivíduo. Na verdade, Vygotsky (1995) compreendia ser essa a tarefa principal da análise psicológica: compreender e explicar como se constitui o processo de individuação.

Para melhor compreensão desse processo, é necessário recorrer ao papel desempenhado pela criação e utilização de signos pela humanidade. O desenvolvimento das funções psíquicas superiores na história da humanidade se caracterizou pelo fato de as mudanças na conduta ocorrerem sem a modificação do tipo biológico do homem; enquanto que as mudanças biológicas são a base do tipo evolutivo de desenvolvimento. No homem, a adaptação ao meio se modificou por completo com o desenvolvimento de seus órgãos artificiais, isto é, as ferramentas que passou a utilizar para modificar a natureza. A utilização das ferramentas modificou, também, seu sistema de movimentos e o das percepções, o cérebro e as mãos, enfim, todo o organismo humano; porém, não foram mudanças anatômicas nesses órgãos ou na estrutura do corpo, mas nas funções exercidas por eles (VYGOTSKY, 1995).

Vygotsky (1995) faz uma analogia entre o emprego de ferramentas para modificação da natureza e a utilização de signos, que define como estímulos artificiais introduzidos pelo próprio homem, meios auxiliares para a solução de alguma tarefa psicológica (memorizar, comparar algo, informar, escolher etc.), quer dizer, são considerados instrumentos da atividade psicológica humana. Ao criar estímulos artificiais, o homem cria "de fora” novas conexões no cérebro, o que significa dizer que sua ação modifica sua própria natureza (VYGOTSKY, 1995).

As semelhanças entre ferramenta e signo residem na atividade mediadora comum a ambos, sua função instrumental. As diferenças estão na sua distinta orientação: a ferramenta está dirigida para o objeto, para operar mudanças neste; é o meio da atividade exterior do homem destinado a modificar a natureza. $\mathrm{O}$ signo não modifica nada no objeto da operação psicológica, é um meio para sua atividade interior, dirigido para dominar o próprio ser humano, sua própria conduta ou a conduta dos demais (VYGOTSKY, 1995).

Apesar da importância da função instrumental dos signos, não podemos perder de vista que o aspecto central e realmente instaurador de novas conquistas para a humanidade foi a relação social mediada pela linguagem. Leontiev (1991) explicita claramente essa questão quando afirma que não se formam ações e operações na criança sob a influência direta dos objetos. As ações estão contidas nos objetos, mas o que leva a criança a formar as capacidades e funções necessárias para a realização dessas ações é o fato de suas relações com o mundo serem mediadas por suas relações com as pessoas.

Aprofundando a discussão sobre a linguagem e o processo de individuação, cabe ressaltar o papel de controle que a linguagem exerce, tanto sobre o comportamento de outros, como sobre o próprio comportamento e pensamento da criança. No início, o signo é sempre um meio de relação social, um meio de influência sobre os demais e só depois se transforma em meio de influência sobre a própria criança. No desenvolvimento da conduta da criança, modifica-se o papel genético do coletivo: no início, as funções superiores de pensamento se manifestam na vida coletiva das crianças e somente depois aparecem em sua própria conduta (VYGOTSKY, 1995).

A compreensão de Vygotsky sobre a fala da criança exemplifica tal questão. Para o autor, a fala inicial da criança é social e multifuncional; posteriormente, as funções da fala diferenciam-se, aparecendo a fala egocêntrica e a fala significativa, entre os dois e os sete anos. A função da primeira é interna, onde 
a criança procura ordenar seus pensamentos; já a segunda é externa, possibilitando à criança a comunicação de seus pensamentos. Ainda, como não diferencia essas duas funções, a criança confunde a fala para si mesma e a fala dirigida ao outro. Dessa forma, a fala egocêntrica assume, para o autor, um papel de transição na evolução da fala oral para a fala interior, ressaltando-se, aqui, a importância do social na construção da representação e da realidade pela criança, pois ela transfere padrões de comportamento inicialmente sociais - para seus processos interiores.

Elucidamos, também, que esse processo com a análise que Vygotsky faz do desenvolvimento do gesto indicativo é considerado a base primitiva de todas as formas superiores de comportamento e com papel fundamental no desenvolvimento da linguagem na criança. Inicialmente, a criança age, manifestando-se com relação ao que pretende conseguir, por exemplo, move os braços em direção ao objeto desejado. A mãe procura ajudá-la e interpreta o movimento como uma indicação. A situação então muda: o gesto indicativo se converte em gesto para outro. O que se modifica é a função do próprio movimento: de gesto dirigido para o objeto, o movimento passa a ser dirigido para outra pessoa, convertendo-se em um meio de relação. A criança é a última a tomar consciência de seu gesto. Seu significado e função se determinam, primeiramente, pela situação objetiva e, em seguida, pelas pessoas que a rodeiam. Parte, então, do gesto indicativo para os outros e só mais tarde se converte em gesto indicativo para a própria criança (VYGOTSKY, 1995).

Isso explica a lei genética do desenvolvimento proposta por Vygotsky (1995): toda função no desenvolvimento cultural da criança aparece em cena duas vezes, em dois planos, primeiro no plano social e depois no psicológico; a princípio entre os homens como categoria interpsíquica e, depois, no interior da criança como categoria intrapsíquica.

Tratando-se da questão específica da linguagem e do pensamento, Vygotsky defende uma unidade, uma dinâmica na relação entre esses dois aspectos do conhecimento. Existe, entretanto, uma gênese diferenciada e, no decorrer do desenvolvimento, ocorre uma associação entre pensamento e linguagem, marcada por contradições e conexões.

Como vimos anteriormente, para Piaget a linguagem não assume importância fundamental na construção do pensamento, sendo a ação responsável pela estruturação da capacidade lógica e da função simbólica na criança. Conforme Vygotsky (1993), porém, a capacidade do indivíduo de lidar com um sistema de signos culturais acarreta a transformação dos seus processos mentais. Para o autor, a linguagem é um dos sistemas mais decisivos na sistematização da percepção e na interpretação da realidade, sendo que diferentes interpretações da realidade revelam diferenças no sistema psicológico do sujeito. Ele interessou-se, entre outras questões, pela formação de conceitos, desejando compreender os estágios em que as palavras aparecem nas interpretações da realidade.

Vygotsky (1993) realizou uma extensa investigação experimental sobre o desenvolvimento dos conceitos na criança, pela qual demonstrou que o aspecto central e imprescindível em todo o processo de formação de conceitos é o uso funcional das palavras como meios para dirigir ativamente a atenção, analisar e destacar os atributos dos objetos, abstrai-los e sintetizá-los. O autor identificou diversas fases nesse processo: desde os agrupamentos, a formação dos vários tipos de complexos, os pseudoconceitos até os conceitos genuínos. Cada uma dessas fases se caracteriza pelo tipo de operação intelectual realizada, especialmente em relação ao significado das palavras. Nesse sentido, as palavras da criança coincidem com as do adulto em sua atribuição aos objetos, têm os mesmos referentes, mas não coincidem nos seus significados; é essa diferença qualitativa que define o pensamento por complexos ou o pensamento por conceitos (VYGOTSKY, 1993).

A inserção dos conceitos em sistemas conceituais organizados, para Vygotsky (1993), exerce um papel decisivo para o desenvolvimento do pensamento. Com base nessa tese, o autor realizou um estudo experimental comparando o desenvolvimento dos conceitos cotidianos, formulados pela criança a partir da sua experiência imediata, e os conceitos científicos aprendidos durante o processo de escolarização. Seu objetivo foi explicitar, no campo concreto da escola, a relação entre ensino e desenvolvimento.

Os conceitos cotidianos se formam com base na experiência concreta da criança, com base na sua percepção imediata. A criança opera espontaneamente com conceitos reais, contudo, de modo inconsciente, isto é, resolve as situações na prática, mas a consciência e a intencionalidade não estão presentes 
no emprego desses conceitos. Em outras palavras, ela não sabe explicar os motivos que a levaram a determinadas escolhas ou as relações de causalidade entre os objetos e as situações (VYGOTSKY, 1993).

Já os conceitos científicos têm um caminho completamente oposto em relação à experiência da criança, pois, no processo de instrução, a criança é ensinada a conhecer algo que não tem diante dos olhos, que está muito além de sua experiência atual e imediata. Ao serem elaborados com o auxílio do professor, os conceitos científicos partem das explicações e conhecimentos que são proporcionados à criança, bem como dos questionamentos, perguntas e correções que resultam da ação pedagógica. Favorecem, dessa forma, a tomada de consciência da criança acerca das suas escolhas e das relações que estabelece entre os objetos ${ }^{5}$. Assim, o que está em pauta não é a experiência direta da criança, mas sua experiência mediada por outros conceitos já elaborados anteriormente, inseridos num sistema, que envolvem relações hierárquicas e de subordinação entre si. Os conceitos científicos pautam-se nos processos intelectuais de abstração e generalização, tendo como decorrência o manejo consciente e voluntário dos conceitos já adquiridos (VYGOTSKY, 1993).

Os conceitos cotidianos estabelecem uma relação de primeira ordem com o objeto, ou seja, a mediação se dá entre o conceito e o próprio objeto. Os conceitos científicos, por outro lado, estabelecem uma relação de segunda ordem com o objeto, uma vez que ocorre uma mediação entre os conceitos científicos e os cotidianos para chegar ao objeto. Quando a criança consegue alcançar o uso funcional do conceito científico, isto é, "descer" até o objeto, essa relação de segunda ordem do conceito científico se transforma em uma relação de primeira ordem com o objeto ${ }^{6}$. Vygotsky (1993) evidencia, no entanto, que a formulação dos conceitos, sejam cotidianos ou científicos, não é o final do processo, mas, ao contrário, apenas o seu início. O processo de formação dos conceitos se inicia, na verdade, no momento em que a criança assimila pela primeira vez o termo novo. É o seu uso que vai garantir a eficácia do conceito como processo de pensamento (VYGOTSKY, 1993).

\section{ALGUMAS CONSIDERACÕES SOBRE OS TEMAS APRESENTADOS}

Pelo exposto até aqui, é possível afirmar a importância das duas teorias analisadas no contexto do debate científico do século XX, especialmente pela amplitude, solidez e rigor metodológico que as caracterizam. Como podemos observar, esses autores enfatizaram em seus trabalhos a discussão sobre as relações entre pensamento e linguagem e também desenvolvimento e aprendizagem.

Pode-se dizer que, para ambos os autores, a aquisição da linguagem, tanto oral como escrita, está relacionada a processos complexos de representação da realidade, o que difere da perspectiva empirista, que entende o domínio da linguagem apenas como um processo de codificação e decodificação de signos. Isso é importante afirmar, considerando o atual contexto educacional, em que muitas das discussões sobre alfabetização retomam aspectos já considerados superados pelos pesquisadores, especialmente quanto à preocupação específica com os métodos e a obtenção de habilidades muito específicas pelas crianças, na tentativa de simplificar um processo que é complexo em sua natureza.

Entendemos que as diferenças entre os autores foram explicitadas ao longo do texto, principalmente quanto aos fundamentos epistemológicos, que levam a consequências na formulação das concepções de desenvolvimento e suas implicações para aprendizagem,

Concordamos com Souza e Kramer (1991, p. 72) quando explicitam alguns dos contrapontos, entre eles:

\footnotetext{
${ }^{5}$ Vygotsky (1993, p. 213-214) entende que o processo de tomada de consciência chega à criança pela porta dos conceitos científicos: "Os conceitos científicos, com suas atitudes totalmente distintas até o objeto, mediados através de outros conceitos com seu sistema hierárquico interno de relações mútuas, constituem a esfera na qual a tomada de consciência dos conceitos, isto é, sua generalização e domínio, surgem pela primeira vez. Depois, esta nova estrutura se transfere a todas as esferas do pensamento e dos conceitos”.

${ }^{6}$ Pode-se aplicar esse mesmo raciocínio ao processo de aquisição da escrita. No primeiro momento, a escrita estabelece uma relação de segunda ordem com os objetos, sendo mediada pela linguagem oral. Com o seu desenvolvimento, a relação da escrita com os objetos passa a ser direta, isto é, de primeira ordem, tornando-se independente da linguagem oral (VYGOTSKY, 1995).
} 
[...] enquanto Piaget busca compreender as estruturas do pensamento a partir dos mecanismos internos que as engendram, Vygotsky procura compreender de que maneira se dá o reflexo do mundo externo no mundo interno, ou seja, como a natureza sociocultural das pessoas se torna igualmente sua natureza psicológica.

As autoras destacam que, ao privilegiar o sujeito histórico e cultural, Vygotsky destaca o contexto social e o papel da internalização do sujeito, entendendo a atividade a partir da sua inserção nas interações mediadas pelos signos linguísticos. Já Piaget, ao privilegiar o sujeito cognoscente, considera a atividade do sujeito destituída de seu conteúdo semântico, tornando-a um desencadeador de mecanismos internos de autorregulamentação, que traduzem uma busca de equilibração progressiva das estruturas cognitivas em sucessivos patamares de complexidade. Concluem as pesquisadoras:

De tudo isso, podemos destacar a insistência de Piaget em proclamar a insuficiência da linguagem na construção das estruturas cognitivas e uma preocupação em enfatizar o papel da inteligência operatória, enquanto para Vygotsky a linguagem é constituidora da consciência, é espaço privilegiado da construção de sentidos (SOUZA; KRAMER, 1991, p. 74).

Se, para Piaget, a tendência do desenvolvimento cognitivo é uma adaptação cada vez maior pela criança à realidade, em função do desenvolvimento do pensamento intuitivo ou pré-lógico, para o pensamento lógico; para Vygotsky, o que preocupa é o que ele chama de potencial de sentido que necessita ser aproveitado pelo indivíduo, ou seja, as possibilidades que esse indivíduo tem de transformar sentidos nas relações dialógicas, que permitirão ou não sua constituição em sujeito.

De um modo geral e tratando-se das questões que nos interessam nessa discussão, compartilhamos da posição de Souza e Kramer (1991, p. 79), as quais entendem que, para Piaget,

[...] tanto a relação pensamento/linguagem como a relação desenvolvimento/aprendizagem são concebidas como aspectos estruturais dicotômicos do fenômeno humano. Em Vygotsky, ao contrário, a interrelação desses aspectos do fenômeno humano é entendida dialeticamente e é sustentada por uma concepção dinâmica do desenvolvimento histórico do sujeito social. Assim, para Piaget, o desenvolvimento do pensamento é a adaptação do indivíduo ao meio físico e social, enquanto para Vygotsky, o desenvolvimento do pensamento é um processo essencialmente dialético, em que o sujeito transforma e é transformado pela realidade física, social e cultural em que se encontra.

Nesse ponto esperamos ter possibilitado aos leitores, e aos professores especialmente, elementos teóricos para compreender a complexidade que envolve o processo de apropriação da linguagem e escrita pela criança, para além de um desenvolvimento meramente orgânico, natural e individual.

De qualquer forma, entendemos que reconhecer a necessidade do professor de ter acesso às teorias sobre a aquisição da realidade e da linguagem como fundamental para a sua prática pedagógica, implica em entender que de posse dessas teorias ele tenderia a relevar o contexto singular e coletivo de cada aluno com o qual trabalha. Assim, por exemplo, ao lidar com alunos de diferentes camadas sociais, o professor conseguiria relevar as variedades linguísticas valorizadas ou estigmatizadas, procurando sair de um lugar possivelmente preconceituoso em relação à aprendizagem. Esse movimento, de relevar as variedades linguísticas e suas relações com contextos econômicos e culturais, estaria explicito para o professor a partir da sua compreensão das teorias de Piaget e Vygotsky sobre aquisição da linguagem e da realidade pela criança.

No contraponto, também a leitura dos professores sobre a apreensão e elaboração de textos escritos pelos alunos passa pela compreensão deles sobre como ocorre no desenvolvimento infantil a construção da linguagem e da realidade. Assim, temos em pauta que a forma como os professores lidam com a linguagem, tanto a falada como a escrita, se associa ao seu entendimento de que não existem necessariamente "erros" ou "atrasos" na aquisição da linguagem e elaboração do real pela criança. Temos diferentes contextos sociais, econômicos e culturais a serem relevados pois, “... O uso, pelos alunos provenientes das camadas populares, de variantes linguísticas social e escolarmente estigmatizadas provoca preconceitos linguísticos e leva a dificuldades de aprendizagem, já que a escola usa e quer ver usada a variante-padrão socialmente prestigiada (SOARES, 1989, p. 17). 
Continuando, no decorrer das análises realizadas sobre os trabalhos dos autores no que diz respeito de forma específica a aquisição da linguagem e da realidade pela criança, também localizamos questões concernentes ao aspecto da alfabetização. Assim, Carvalho (2000) indica que é ainda muito comum entre os professores, particularmente os alfabetizadores, a ideia de que a alfabetização é compreendida mais como uma aquisição cognitiva e pessoal da criança do que como um processo de inserção social e cultural. Do mesmo modo, os professores atribuem importância ao processo de alfabetização, “(...) mais pelas conquistas práticas e imediatas obtidas pela criança no seu dia a dia, do que pelas mudanças que o este processo acarreta para o psiquismo infantil, especialmente quanto à possibilidade de um pensamento crítico e reflexivo" (CARVALHO, 2000, p. 81).

Compreendemos que a linguagem oral e a aquisição da linguagem escrita possibilitam a comunicação com o outro e conosco, na medida em que viabilizam a materialização da nossa sensibilidade e a codificação e sistematização da realidade; a sua codificação passa, não só pelo domínio, mas, principalmente, pela apreensão e recriação desse código linguístico. É neste sentido que se coloca a relação entre a prática do professor e sua compreensão das teorias dos autores que analisamos.

Em outras palavras, as práticas de leitura e de escrita em nossa sociedade influenciam as crianças nas interpretações que elas fazem sobre a realidade, bem como, as instrumentalizam para o processo de escolarização. De forma específica, no caso da escolarização é importante comentar que entendemos que o debate aqui proposto pode trazer contribuições para a formação de professores, pois compreender os fundamentos teóricos e epistemológicos de cada teoria permite que o professor tenha mais clareza de suas escolhas metodológicas.

\section{REFERÊNCIAS}

BERGER, P. L.; LUCKMANN, T. A Construção social da realidade. Petrópolis, RJ: Vozes, 1985.

BLEGER, J. Temas de psicologia entrevista e grupos. São Paulo: Martins Fontes, 1980.

CAMBI, F. História da Pedagogia. São Paulo: Editora da UNESP, 1999.

CARVALHO, D. C. de. A relação entre Psicologia e alfabetização sob a óptica dos professores. 2000. 223p. Tese (Doutorado em Educação) - Pontifícia Universidade Católica de São Paulo, São Paulo, 2000.

CASTORINA, J. A. et al. Piaget-Vygotsky: novas contribuições para o debate. 5. ed. São Paulo: Ática, 1998.

DUARTE, N. (org.). Sobre o construtivismo: contribuições a uma análise crítica. Campinas, SP: Autores Associados, 2000a.

DUARTE, N. Vigotski e o “aprender a aprender”: críticas às apropriações neoliberais e pósmodernas da teoria vigotskiana. Campinas, SP: Autores Associados, $2000 \mathrm{~b}$.

FREITAS, M. T. A. O pensamento de Vygotsky e Bakhtin no Brasil. Campinas, SP: Papirus, 1994.

KATO, M. O aprendizado da leitura. São Paulo: Martins Fontes, 1987.

KATO, M. (org.). A Concepção da escrita pela Criança. Campinas, SP: Pontes, 1988.

LEITE, D. M. O desenvolvimento da criança: leituras básicas. São Paulo: Editora Nacional; Editora da USP, 1972.

LEONTIEV, A. N. Os princípios do desenvolvimento mental e o problema do atraso mental. In: LURIA, A. R. et al. Psicologia e pedagogia: bases psicológicas da aprendizagem e do desenvolvimento. 2. ed. Lisboa: Estampa, 1991. v. 1. p. 99-119.

LOURENÇO FILHO, M. B. Introdução ao estudo da escola nova. 2. ed. São Paulo: Melhoramentos, 1930. 
LURIA, A. R. O papel da linguagem na formação de conexões temporais e a regulação do comportamento em crianças normais e oligofrências. In: LURIA, A. R. et al. Psicologia e pedagogia: bases psicológicas da aprendizagem e do desenvolvimento. 2. ed. Lisboa: Estampa, 1991. v. 1. p. 121-141.

PALANGANA, I. C. Desenvolvimento e aprendizagem em Piaget e Vygotsky: a relevância do social. São Paulo: Plexus, 1994.

PIAGET, J. A construção do real na criança. Rio de Janeiro: Zahar, 1970.

PIAGET, J. Seis estudos de Psicologia. Rio de Janeiro: Forense, 1973.

PIAGET, J. A formação do símbolo na criança. imitação, jogo e sonho: imagem e representação. Rio de Janeiro: Zahar, 1975.

SGANDERLA, A. P.; CARVALHO, D. C. A Psicologia e a constituição do campo educacional brasileiro. Psicologia em Estudo, Maringá, PR, v. 15, n. 1, p. 107-115, 2010.

SMOLKA, A. L. B. Estatuto de sujeito, desenvolvimento humano e teorização sobre a criança. In: FREITAS, M. C.; KUHLMANN JUNIOR, M. (org.). Os intelectuais na história da infância. São Paulo: Cortez, 2002. p. 99-127.

SOARES, M. Linguagem e escola: uma perspectiva social. São Paulo: Ática, 1989.

SOUZA, S. J.; KRAMER, S. O debate Piaget e Vygotsky e as políticas educacionais. Cadernos de Pesquisa, São Paulo, n. 77, p. 69-80, 1991.

VASCONCELOS, M. S. A difusão das idéias de Piaget no Brasil. São Paulo: Casa do Psicólogo, 1996.

VYGOTSKY, L. S. El significado histórico de la crisis de la psicolgía: una investigación metodológica. In: VYGOTSKI, L. S. Obras Escogidas. Madrid: Visor, 1991. v. 1. p. 257-413.

VYGOTSKY, L. S. Pensamiento y lenguaje. In: VYGOTSKI, L. S. Obras Escogidas. Madrid: Visor, 1993. v. 2. p. 9-348.

VYGOTSKY, L. S. Historia del desarrollo de las funciones psíquicas superiores. In: VYGOTSKI, L.

S. Obras Escogidas. Madrid: Visor, 1995. v. 3. p. 11-340.

WARDE, M. J. Para uma história disciplinar: psicologia, criança e pedagogia. In: FREITAS, M. C. (org.). História social da infância no Brasil. São Paulo: Cortez, 1997. p. 289-310. 